DR. MARI MULDMAA (Orcid ID : 0000-0001-8241-9937)

DR. LIIS KADASTIK-EERME (Orcid ID : 0000-0002-9788-9402)

Article type : Original Article

\title{
Community-based genetic study of Parkinson's disease in Estonia
}

A running title: Estonian PD genetic study

Author's names: Mari Muldmaa, $\mathrm{MD}^{1,2}$, Niccolò Emanuele Mencacci, MD, PhD ${ }^{3}$, Alan Pittman, $\mathrm{PhD}^{4}$, Liis Kadastik-Eerme, MD, $\mathrm{PhD}^{5}$, Katrin Sikk, MD, PhD², Pille Taba, MD, PhD ${ }^{1,5}$, John Hardy, $\mathrm{PhD}^{4,6}$, Sulev Kõks, MD, $\mathrm{PhD}^{7,8}$

Affiliations: ${ }^{1}$ Department of Neurology and Neurosurgery, Institute of Clinical Medicine, University of Tartu, Tartu, Estonia

${ }^{2}$ Department of Neurology, North Estonia Medical Centre, Tallinn, Estonia

${ }^{3}$ Department of Neurology, Northwestern University Feinberg School of Medicine, Chicago, IL, USA

${ }^{4}$ Department of Molecular Neuroscience, UCL Institute of Neurology, Queen Square, London, UK

${ }^{5}$ Neurology Clinic, Tartu University Hospital, Tartu, Estonia

${ }^{6}$ Department of Neurodegenerative Disease, Reta Lila Weston Laboratories, Queen Square Genomics, UCL Dementia Research Institute, London, UK

This article has been accepted for publication and undergone full peer review but has not been through the copyediting, typesetting, pagination and proofreading process, which may lead to differences between this version and the Version of Record. Please cite this article as doi: 10.1111/ANE.13329

This article is protected by copyright. All rights reserved 
${ }^{7}$ Centre for Molecular Medicine and Innovative Therapeutics, Murdoch University, Perth, WA, Australia

${ }^{8}$ The Perron Institute for Neurological and Translational Science, Nedlands, 6009, Perth, WA, Australia

Corresponding author: Sulev Kõks, e-mail: sulevkoks@gmail.com, telephone: +61 864570313 fax: + 61864570333

Centre for Molecular Medicine and Innovative Therapeutics, Murdoch University, Perth, WA, Australia/The Perron Institute for Neurological and Translational Science, Nedlands, 6009, Perth, WA, Australia

\section{Acknowledgments}

This study was supported by the Grants PUT1239 and PRG957 of the Estonian Research Council and by the MSWA. Niccolo Mencacci is funded by a Parkinson's Foundation grant.

The authors thank all patients and controls as well as all referring neurologists and nurses for participating in this study. Also, we thank Ele Prans for her help in separating DNA.

This article is protected by copyright. All rights reserved 


\section{ABSTRACT}

Objective: To examine the genetic variability of Estonian Parkinson's disease (PD) patients using an ongoing epidemiological study in combination with a genetic analysis.

Methods: This study was a community-based genetic screening study of 189 PD patients and 158 age and sex matched controls screened for potential mutations in 9 PD genes using nextgeneration sequencing and multiplex ligation-dependent probe amplification method. Different clinimetric scales and questionnaires were used to examine PD patients and assess clinical characteristics and severity of the disease.

Results: The overall frequency of pathogenic PD-causing variants was $1.1 \%(2 / 189)$, any rare genetic variant was present in $21.2 \%$ (40/189) of the patients and in $8.2 \%(13 / 158)$ of the controls $(p<0.05)$. Variants of unknown significance accounted for $10.6 \%(20 / 189)$. Frequency of any GBA variant among PD patients was $10.1 \%$ (19/189) and in controls $3.8 \%(6 / 158)$. The frequency of any GBA variant in PD compared to controls was significantly higher ( $p=0.035$; OR 2.82; $\mathrm{Cl} 95 \%$ 1.05-8.87). Burden of rare variants was not different between patients and controls. Also, a novel GBA pathogenic variant p.E10X was detected.

Conclusion: Among different genetic variants identified in Estonian PD patients, GBA variants are the most common while an overall pathogenic variant frequency was $1.1 \%$.

Key words: Parkinson's disease, genetics, next generation sequencing, multiplex ligationdependent probe amplification 


\section{Introduction}

Parkinson's disease (PD) is the second most common neurodegenerative disease with a global crude prevalence of $2-3 \%$ in people $\geq 65$ years of age. ${ }^{1}$ Although mostly thought to be caused by a combination of environmental and genetic risk factors, about $15 \%$ of the patients have positive family history and $5-10 \%$ have a specific monogenetic form with Mendelian inheritance. ${ }^{2}$

The first PD related gene, $\alpha$-synuclein, was discovered in $1997^{3}$ and ever since at least 19 disease causing genes and 23 loci have been reported. In addition, genome wide associations studies have detected multiple genes and loci that increase the risk of PD. ${ }^{4}$ Estonia lies in the NorthEastern part of Europe and has a population of about 1.3 million. The age-adjusted prevalence of PD is $314 / 100000^{5}$ so there are about 4000 PD patients in Estonia.

Native Europeans, in general, are genetically relatively homogenous, but still have a northwest to southeast gradient in genetic diversity that correlates with geography. ${ }^{6}$

The genetic structure of North-Eastern Europeans has been well described and reveals that Estonians cluster together with their neighbours Latvians and Lithuanians, as well as with Western Russians and Poles, leaving the Finnish population to a separate cluster. ${ }^{7}$ At the same time, there are intra-population differences, with South-Eastern Estonians being genetically very close to Latvians, whereas Northern Estonians share more with Southern Finns. ${ }^{8}$

This study implemented a community-based approach to examine the genetic variability of Estonian PD patients, gathering data from an ongoing PD epidemiological study combined with genetic analysis. A gene panel was designed in the University College London's Institute of Neurology, and included already established PD-causing genes as well as more recently PD-linked risk variants (Box 1). ${ }^{9,10}$

This article is protected by copyright. All rights reserved 


\section{Methods}

\section{Subjects}

The current study was a community-based genetic screening study. Cases consisted of 189 PD patients of Estonian descent who had been previously diagnosed according to the Queen Square Brain Bank (QSBB) criteria ${ }^{11}$ and treated in the Tartu University Hospital's Neurology Clinic. The patients enrolled in this study were also a part of the larger cross-sectional study that aimed to evaluate the prevalence and incidence of PD in Estonia. ${ }^{5} 22$ patients had a positive family history for PD in a first degree relative, and 9 patients in a distant relative. Early onset PD was defined by the age of onset below 50 years.

Comparison was made with 158 age and sex matched controls of the Estonian descent. The controls were recruited from the Tartu University Hospital's Neurology Outpatient Clinic, and comprised of patients without any known central nervous system disease. All participants reported "white" ethnicity.

The following clinimetric scales were used to assess PD patients: the Movement Disorders Society's Unified Parkinson's Disease Rating Scale (MDS-UPDRS) ${ }^{12}$, the Hoehn and Yahr Scale $(\mathrm{HY})^{13}$, the Schwab and England Activities of Daily Living Scale (SE-ADL) ${ }^{14}$, the Beck Depression Inventory $(\mathrm{BDI})^{15}$ and the Mini Mental State Examination (MMSE). ${ }^{16}$ Disease subtypes were based upon the most prevalent symptom during a standard neurological examination: tremor; bradykinesia-hypokinesia; or postural instability gait disorder (PIGD).

The study was approved by the Research Ethics Committee of the University of Tartu. A written informed consent was obtained from all patients and controls.

This article is protected by copyright. All rights reserved 


\section{Genetic analysis}

A pathogenic variant was defined as a variant that has been previously shown to be causative for autosomal dominant or recessive PD or to be an established risk allele for PD. A novel pathogenic variant was defined as a previously unreported loss-of-function variant in a gene for which lossof-function is an established mechanism.

Peripheral blood was obtained from PD patients and controls. Genomic DNA (gDNA) was extracted from the whole blood by the salting out protocol. ${ }^{17}$

Both PD patients and controls were screened for potential mutations across 117 exons in 9 PD genes using next-generation sequencing (NGS) with Illumina's MiSeq sequencer and polymerase chain reaction (PCR) amplicon-based (TruSeq custom amplicon) target enrichment. TruSeq custom amplicon assay Design Studio v1.6 online was used to design the probes. The assay was performed following the manufacturer's recommended protocol. Exons not covered at all by at least 10 reads (PRK7/DJ1, PINK1, GBA, PRKN/PARK2, LRRK2 and GCH1) were subsequently Sanger sequenced. Variants with minor allele frequency (MAF) $\geq 1 \%$ in general population according to 1000 Genome Project (www.1000genomes.org) were excluded from the analysis. PCR primers and conditions are available upon request.

All familial and early onset PD cases were screened by multiplex ligation-dependent probe amplification (MLPA) method looking for duplication and triplication of SNCA, copy number variations (CNVs) in PRKN, PRK7, PINK1 and point mutation in LRRK2 G2019S and SNCA A30P. Copy number variations were also looked for in carriers of heterozygous missense mutations in recessive genes. The P051-C3 Salsa MLPA Parkinson probe set was used (MRC Holland, Amsterdam, the Netherlands). Data were analyzed using Genemarker, version 2.6.2, software.

$91.3 \%$ of the exons were completely covered by at least 10 reads. $1.7 \%$ of the exons were covered for the $50-99 \%$ by at least 10 reads. $7 \%$ of the exons failed (not covered at all by at least 10 reads): $P R K 7 \times 4, P I N K 1 \times 6, G B A \times 3, P R K N \times 8, L R R K 2 \times 41-\times 45-x 49$ and GCH1x1 and were Sanger sequenced.

\section{Statistical analysis}

This article is protected by copyright. All rights reserved 
Statistical analysis was conducted using R software (version 1.1.383). The level of significance was set to 0.05 . Fisher exact test was used for comparing variation frequencies between PD patients and controls and calculating odds ratios.

This article is protected by copyright. All rights reserved 


\section{Results}

A total of 189 patients with PD (113 women, 76 men) and 158 controls ( 96 women, 62 men) comprised the study group. The descriptive statistics of the clinimetric scales, the data on the clinical subtypes and the family history of PD patients are shown in Table 1.

The mean age of PD patients and controls at examination were $72.5 \pm 8.4$ years (range $47-87$ ) and $72.0 \pm 9.1$ years (range $47-95$ ), respectively. The mean age at PD onset was $65.2 \pm 10.1$ years (range $35-83$ ), and the duration of PD $7.3 \pm 5.6$ years (range $0.3-35$ ). 17 early onset PD cases were identified including 3 cases with PD onset before 40 years. Any rare genetic variant was present in $21.2 \%(40 / 189)$ of the patients and in $8.2 \%(13 / 158)$ of the controls. Of all the rare variants detected in PD patients, the frequency of pathogenic PD-causing variants was $1.1 \%(2 / 189)$, both patients were carriers of single mutations in a recessive gene and had negative MLPA. The frequency of $G B A$-related risk variants was 9.5\% (18/189) and variants on unknown significance accounted for $10.6 \%(20 / 189)$.

Three patients carried more than one variant: first patient carried three different variants in $G B A$, PRK7 and PINK1, another patient had two different variants in GBA and GHC1, and one patient had also two different variants in GBA and PRK7.

Three different pathogenic variants were identified in four PD patients: two patients carried a single heterozygous pathogenic variant in PRKN, one patient was a carrier of Gaucher's disease causing variant in $G B A$, and another patient carried a novel pathogenic variant in GBA.

Out of all patients with a positive family history (PD in 22 first degree relatives and in 9 distant relatives), only five patients carried rare risk variants or variants with unknown significance, and no one carried pathogenic variants.

No duplication or triplication of SNCA, copy number variations in PRKN, PRK7, PINK1 and point mutation in LRRK2 G2019S and SNCA A30P were detected. No variants in DCTN1 were found. No cases with homozygous or compound heterozygous mutations in recessive genes (PRKN, PINK1, PRK7) were identified.

Summary of the genetic findings is presented in Table 2 and the frequencies of rare variants are shown in Table 3. 


\section{GBA}

Five different variants were identified in the GBA gene. Frequency of any GBA variant among PD patients was $10.1 \%$ (19/189, MAF 0.05) and in controls 3.8\% (6/158, MAF 0.018). The frequency of any GBA variant in PD compared to controls was significantly higher than in controls ( $p=$ 0.035; OR 2.82; $\mathrm{Cl} 95 \%$ 1.05-8.87). Novel or pathogenic mutations were found in three patients and in none of the controls. A novel GBA pathogenic variant p.E10X is likely to result in haploinsufficiency. Also, a novel variant of unknown significance p.L276I was detected in one patient and one patient carried a pathogenic variant L444P that in homozygous state causes severe form of Gaucher's disease (types 2 and 3).

The difference between PD and controls was not significant for GBA common risk factors (T369M and E326K) for PD, however compared to other Caucasian controls there is an excess of T369M in $\mathrm{PD}$ cases (MAF=0.0265 in the Estonian cohort versus $\mathrm{MAF}=0.011$ in a recent meta-analysis ${ }^{18}$ ).

\section{GCH1}

Two different variants were identified in PD patients only (p.V204I in two and p.Q110E in one PD patient), reported in detail elsewhere. ${ }^{19}$

\section{LRRK2}

Three different variants were found in the $L R R K 2$ gene. The frequency of any $L R R K 2$ variant was $3.7 \%$ (7/189) among PD patients and 2.5\% (4/158) in controls. No p.G2019S was detected in early onset or familial PD. Two patients and one control carried the variant p.E334K, four patients and three controls carried the variant p.R1514Q and the variant p.R767H was found in one patient only. 23 PD patients had the variant p.P1542S (MAF 0.06) but it was present at similar frequency in controls. However, for Estonian PD patients vs Caucasian controls the OR is 1.8. Overall, burden of rare variants did not differ between PD patients and controls.

\section{VPS35}

Only one variant of unknown significance (p.G51S) was found in one PD patient and one control.

\section{Recessive genes}

This article is protected by copyright. All rights reserved 
Burden of rare variants was not different in PD patients versus controls. One $P R K 7$ variant (p.R98Q) was found in four PD patients and in none of the controls. Considering PRKN, two different variants were identified in PD patients: a pathogenic heterozygous variant ( $p . R 275 W)$ was detected in two PD patients, MLPA excluded the presence of a second mutation. An additional variant of unknown significance (p.V109M) was identified in another patient. Also, a heterozygous variant p.A82E was identified in three controls but in none of the PD patients.

Regarding PINK1, three different variants were present in three patients and two controls. One patient carried the variant p.K186N, one patient and two controls had the variant p.G411S and one patient carried the variant p.P209L.

This article is protected by copyright. All rights reserved 


\section{Discussion}

The aim of this study was to explore the genetic variability of Estonian PD patients using a community-based approach. To our knowledge, this is the first report of its kind in the Baltic region, as there are no similar genetic studies available for Latvian and Lithuanian PD populations.

The present study identified a pathogenic variant frequency of $1.1 \%$ that is comparable to the UK's Tracking Parkinson's study, the largest multicentre clinico-genetic incidence study in the world, where a pathogenic variant frequency of $1.4 \%$ was reported. ${ }^{20}$ These low frequencies are interesting when considering that the general opinion is that 5-10\% of PD patients have a genetic cause. It might be that previously described PD-linked variants do not contribute to PD in the Estonian cohort in the level as they contribute in other cohorts. Also, a relatively small sample size may set a limit to the generalizability of these results.

The most common PD associated pathogenic variant LRRK2 p.G2019S was not found in this study. Similarly, a recent Finnish study reported no p.G2019S point mutation in their cohort. ${ }^{21}$ It is known that the frequency of p.G2019S has a geographical north to south gradient and can range from $0 \%$ to up to $35.7 \%$ in sporadic and $42 \%$ in familial North-African Arab patients. ${ }^{22}$ In the Scandinavian-Baltic region, LRKK2 p.G2019S is most frequent in Norwegian PD population, where its overall frequency is $2.1 \%$ which rises up to $9.2 \%$ in familial cases. ${ }^{23}$ Haplotype analysis has revealed common founders for p.G2019S in different ethnic groups ${ }^{24}$ and a Norwegian study suggests that the variant was imported to Norway before the $17^{\text {th }}$ century through tradesman from Europe. ${ }^{25}$ LRRK2 p.G2019S is also relatively common in North-Western Russian PD cohort, where it is present in $1.6 \%$ of all patients and in $5.3 \%$ of familial cases. ${ }^{26}$

LRRK2 p.E334K detected in two patients and in one control has been previously reported as a possible rare risk variant, however it has been thought that due to its overall low frequency more studies are needed to draw conclusions. ${ }^{27}$

The $L R R K 2$ variant p.1514Q was detected in $2.1 \%$ in Estonian PD patients and $1.9 \%$ in Estonian controls. An earlier analysis of p.1514Q in three different European case-control series reported 
the total frequency of $2.2 \%$ in patients and $1.6 \%$ in controls, concluding that it is not linked to increased risk of PD. ${ }^{28}$

The LRRK2 variant p.P1542S was present at similar frequency in PD patients and controls, although the odds ratio compared to other Caucasian controls is slightly elevated for Estonian PD patients. The variant has previously been reported not to be associated with susceptibility to $\mathrm{PD}^{27}$, so it is possible that this variant is just more frequent in the Estonian population.

The largest number of different variants was encountered in the GBA gene. It is expected, as in general GBA mutations are the most common genetic risk factors for PD. ${ }^{29}$ In our study, the frequency of any GBA variant was $10.1 \%$ which is similar to the findings of a recent study in the UK. ${ }^{30}$ Interestingly, the odds ratio for any GBA variant among Estonian PD patients versus controls was about twice lower than in a large multinational multicentre study (OR 2.82 versus 5.43 respectively). ${ }^{31}$ However, there are known ethnic differences also shown by the aforementioned study with similar odds ratios reported for example in the cohorts of National Human Genome Research Institute and Rostock, Germany.

The most common PD-linked GBA variants world-wide are L444P and N370S, which are present in approximately $15 \%$ of Ashkenazi Jewish and in $3 \%$ of non-Ashkenazi Jewish patients. ${ }^{31}$ In European PD patients these variants account for $70 \%$ of all mutant GBA alleles. ${ }^{32}$

Only one case of L444P (frequency of 0.5\%) was found in the Estonian PD cohort and no N370S was detected. As GBA N370S is known to be very common among Ashkenazi Jewish patients ${ }^{33}$ and less so in other populations, it was surprising to find just one Estonian carrier of L444P. When looking at the Scandinavian-Baltic region, GBA L444P appears to be the most frequent in Northern Sweden. A large Swedish case-control study revealed that the overall frequency of L444P was 2.2\%, but there were significant geographical differences. ${ }^{34}$ Namely, L444P was more common in Northern Sweden, where it was detected in 4.11\% of PD patients. Northern Sweden also has a higher prevalence for Gaucher's disease. ${ }^{34}$ L444P is present in $2 \%$ of Finnish PD patients ${ }^{21}$ and in $1.1 \%$ of North-Western Russian PD patients. ${ }^{26}$ It remains unclear whether our finding is an underestimation due to a smaller cohort size or not.

$8.5 \%$ of the $G B A$ variance reported in the Estonian study is made up of $G B A$ frequent variants T369M and E326K. Both are considered to act as PD risk variants with mild effect. ${ }^{18,35}$

This article is protected by copyright. All rights reserved 
This study also reported a novel GBA stopgain variant p.E10x which causes haploinsufficiency that has recently been shown to accelerate $\alpha$-synuclein related pathology by altering lipid metabolism in a mouse model. ${ }^{36}$

The only generally accepted VPS35 pathogenic variant to date is the point mutation p.D620N with a frequency of $0.1 \%-1 \%$ in autosomal-dominant familial PD. ${ }^{37,38}$ Therefore, it is not surprising that the variant was not found in the Estonian cohort. The only variant reported herein, p.G51S, has so far not been associated with PD. ${ }^{39,40}$

The only known PD causing variant detected in the current study was $P R K N$ p.R275W in a heterozygous state in two patients. Both patients were late-onset cases and had no positive family history. Indeed, it is debated whether heterozygous variants in recessive genes alter the risk for developing PD or not. ${ }^{41,42,43}$ Furthermore, the heritability of PD is probably more complex than generally thought. ${ }^{44,45,46}$

An interesting finding to illustrate that is the possible autosomal-dominant behaviour with complete or incomplete penetrance of PINK1 variant p.G411S, ${ }^{47,48}$ A recent thorough multicentre case-control study provided evidence for a partial dominant-negative function of heterozygous p.G411S and established it as a rare genetic risk factor. The same study also speculated that other variants in recessive genes might increase the risk for late-onset PD over time and that the level of disease penetrance might be dependent on the level of mitochondrial stress. ${ }^{49}$ However, the role of this variant is still controversial with other reports indicating that p.G411S is likely not pathogenic. ${ }^{50}$

At present, other variants found in the Estonian cohort in recessive genes ( $P I N K, P R K N, P R K 7)$ are all of unknown significance.

Variants with unknown significance were reported with a frequency of $10.6 \%$ in our study. The frequency and role of such variants have recently been analyzed in two large independent cohorts. ${ }^{51}$ The analysis concluded that PD patients with a known pathogenic variant have an excess of additional rare variants with unknown significance compared to PD patients without a known pathogenic variant and controls showing that the burden of such variants might influence the onset and presentation of PD.

This article is protected by copyright. All rights reserved 
Unfortunately, this study failed to show the same results as the burden of rare variants was not different between Estonian PD patients and controls and the two patients who were carrying a known pathogenic variant did not carry any other variant.

A low number of early onset PD cases in the current cohort explains the fact that no homozygous or compound heterozygous cases were found.

The strength of this study is definitely the inclusion of a broad range of patients in the population, regardless of their age at PD onset, family history or genetic profile. In addition, community-based approach can be considered as a major strength, because it helps to ensure genetic homogeneity among the study cohort and by that limits possible confounding (population stratification).

A minor limitation of the study is not having assessed systematically CNVs in recessive genes in all samples. Indeed, CNVs in SNCA, PRKN, PINK1, PRK7 were screened by MLPA only in early onset PD, PD with positive family history and carriers of heterozygous missense mutations in recessive genes. It is still debated whether single heterozygous CNVs are risk factors for late onset PD. 52

While we used clear and concise definitions for pathogenic variants in present paper, the definition of pathogenicity remains a matter of debate. Current definitions are based on genecentric annotations where the causative gene or mutation is either already defined or predictable. However, considering the missing heritability problem, some of the pathogenic variants are possibly hidden in the non-coding regions of the genome where the pathogenic mechanisms are often elusive. These mechanisms can involve altered splicing or changed transcriptional efficiency and therefore are not discoverable by the gene-centric approach. We are still on our way to discover the functional impact of the non-coding variants. That was out of the scope of the present manuscript, but certainly deserves attention in our future studies.

In conclusion, this is the first PD genetic screening study in the Baltics. We have identified the frequencies of different genetic variants for Estonian PD patients and found an overall pathogenic variant frequency of $1.1 \%$. Knowing the country-specific genetic profile of PD patients will be of great help in the coming future when treatments aimed at genetic targets, namely LRRK2 and GBA, will become available. 


\section{Conflict of Interest}

The authors have no conflict of interest to report.

\section{Data Availability Statement}

The data that support the findings of this study are available from the corresponding author upon reasonable request.

This article is protected by copyright. All rights reserved 


\section{References}

1. Poewe W, Seppi K, Tanner CM, et al. Parkinson disease. Nat Rev Dis Primer. 2017;3:1-21.

2. Kalinderi K, Bostantjopoulou S, Fidani L. The genetic background of Parkinson's disease: current progress and future prospects. Acta Neurol Scand. 2016;134:314-326.

3. Polymeropoulos MH, Lavedan C, Leroy E, et al. Mutation in the alpha-synuclein gene identified in families with Parkinson's disease. Science. 1997;276:2045-2047.

4. Deng H, Wang P, Jankovic J. The genetics of Parkinson disease. Ageing Res Rev. 2018;42:72-85.

5. Kadastik-Eerme L, Taba N, Asser T, Taba P. The increasing prevalence of Parkinson's disease in Estonia. Acta Neurol Scand. 2018;138:251-258.

6. Lao O, Lu TT, Nothnagel M, et al. Correlation between Genetic and Geographic Structure in Europe. Curr Biol. 2008;18:1241-1248.

7. Nelis M, Esko T, Mägi R, et al. Genetic structure of europeans: A view from the north-east. PLoS ONE. 2009;4(5):e5472.

8. Haller T, Leitsalu L, Fischer K, et al. MixFit: Methodology for computing ancestry-related genetic scores at the individual level and its application to the estonian and finnish population studies. PLoS ONE. 2017;12:1-14.

9. Brás J, Guerreiro R, Hardy J. SnapShot: Genetics of Parkinson's disease. Cell. 2015;160:570-570.

10. Shen C, Honda H, Suzuki SO, et al. Dynactin is involved in Lewy body pathology. Neuropathology. 2018;38:583-590.

11. Lees AJ, Hardy J, Revesz T. Parkinson's disease. The Lancet. 2009;373:2055-2066.

12. Goetz CG, Tilley BC, Shaftman SR, et al. Movement Disorder Society-Sponsored Revision of the Unified Parkinson's Disease Rating Scale (MDS-UPDRS): Scale presentation and clinimetric testing results. Mov Disord. 2008;23:2129-2170.

13. Hoehn MM, Yahr MD. Parkinsonism: onset, progression, and mortality. Neurology. 1967;17:427-427. 
14. Schwab RS, England AC. Projection technique for evaluating surgery in Parkinson's disease. Third Symp Park Dis. 1969;Edinburgh:152-157.

15. Beck RC, Triplett MF. Test-retest reliability of a group-administered paper-pencil measure of delay discounting. Exp Clin Psychopharmacol. 2009;17:345-355.

16. Folstein MF, Folstein SE, McHugh PR. \&quot;Mini-mental state\&quot;. A practical method for grading the cognitive state of patients for the clinician. J Psychiatr Res. 1975;12:189-198.

17. Miller SA, Dykes DD, Polesky HF. A simple salting out procedure for extracting DNA from human nucleated cells. Nucleic Acids Res. 1988;16:1215.

18. Mallett V, Ross JP, Alcalay RN, et al. GBA p.T369M substitution in Parkinson disease: Polymorphism or association? A meta-analysis. Neurol Genet. 2016;2(5):e104.

19. Mencacci NE, Isaias IU, Reich MM, et al. Parkinson's disease in GTP cyclohydrolase 1 mutation carriers. Brain. 2014;137:2480-2492.

20. Tan MMX, Malek N, Lawton MA, et al. Genetic analysis of Mendelian mutations in a large UK population-based Parkinson's disease study. Brain. 2019;142:2828-2844.

21. Ylönen S, Siitonen A, Nalls MA, et al. Genetic risk factors in Finnish patients with Parkinson's disease. Parkinsonism Relat Disord. 2017;45:39-43.

22. Correia Guedes L, Ferreira JJ, Rosa MM, Coelho M, Bonifati V, Sampaio C. Worldwide frequency of G2019S LRRK2 mutation in Parkinson's disease: A systematic review. Parkinsonism Relat Disord. 2010;16:237-242.

23. Aasly JO, Toft M, Fernandez-Mata I, et al. Clinical features of LRRK2-associated Parkinson's disease in central Norway. Ann Neurol. 2005;57:762-765.

24. Kachergus J, Mata IF, Hulihan M, et al. Identification of a Novel LRRK2 Mutation Linked to Autosomal Dominant Parkinsonism: Evidence of a Common Founder across European Populations. Am J Hum Genet. 2005;76:672-680.

25. Johansen KK, Hasselberg K, White LR, Farrer MJ, Aasly JO. Genealogical studies in LRRK2-associated Parkinson's disease in central Norway. Parkinsonism Relat Disord. 2010;16:527-530.

This article is protected by copyright. All rights reserved 
26. Emelyanov AK, Usenko TS, Tesson C, et al. Mutation analysis of Parkinson's disease genes in a Russian data set. Neurobiol Aging. 2018;71:267.e7-267.e10.

27. Ross OA, Soto-Ortolaza Al, Heckman MG, et al. Association of LRRK2 exonic variants with susceptibility to Parkinson's disease: a case-control study. Lancet Neurol. 2011;10:898-908.

28. Toft M, Mata IF, Ross OA, et al. Pathogenicity of the Lrrk2 R1514Q substitution in Parkinson's disease. Mov Disord. 2007;22:389-392.

29. Schapira AHV. Glucocerebrosidase and Parkinson disease: Recent advances. Mol Cell Neurosci. 2015;66:37-42.

30. Malek N, Weil RS, Bresner C, et al. Features of GBA-associated Parkinson's disease at presentation in the UK Tracking Parkinson's study. J Neurol Neurosurg Psychiatry. 2018;89:702-709.

31. Sidransky E, Nalls MA, Aasly JO, et al. Multicenter Analysis of Glucocerebrosidase Mutations in Parkinson's Disease. N Engl J Med. 2009;361:1651-1661.

32. Lesage $\mathrm{S}$, Anheim $\mathrm{M}$, Condroyer $\mathrm{C}$, et al. Large-scale screening of the Gaucher's disease-related glucocerebrosidase gene in Europeans with Parkinson's disease. Hum Mol Genet. 2011;20:202-210.

33. Ruskey JA, Greenbaum L, Roncière L, et al. Increased yield of full GBA sequencing in Ashkenazi Jews with Parkinson's disease. Eur J Med Genet. 2019;62:65-69.

34. Ran C, Brodin L, Forsgren L, et al. Strong association between glucocerebrosidase mutations and Parkinson's disease in Sweden. Neurobiol Aging. 2016;45:212.e5-212.e11.

35. Huang Y, Deng L, Zhong Y, Yi M. The Association between E326K of GBA and the Risk of Parkinson's Disease. Park Dis. 2018;2018:1048084.

36. Ikuno $M$, Yamakado $H$, Akiyama $H$, et al. GBA haploinsufficiency accelerates alpha-synuclein pathology with altered lipid metabolism in a prodromal model of Parkinson's disease. Hum Mol Genet. 2019;28:1894-1904.

37. Kumar KR, Weissbach A, Heldmann M, et al. Frequency of the D620N mutation in VPS35 in Parkinson disease. Arch Neurol. 2012;69:1360-1364.

This article is protected by copyright. All rights reserved 
38. Trinh J, Zeldenrust FMJ, Huang J, et al. Genotype-phenotype relations for the Parkinson's disease genes SNCA, LRRK2, VPS35: MDSGene systematic review. Mov Disord. 2018;33:1857-1870.

39. Rahman AA, Morrison BE. Contributions of VPS35 Mutations to Parkinson's Disease. Neuroscience. 2019;401:1-10.

40. Sharma M, loannidis JPA, Aasly JO, et al. A multi-centre clinico-genetic analysis of the VPS35 gene in Parkinson disease indicates reduced penetrance for disease-associated variants. J Med Genet. 2012;49:721-726.

41. Klein C, Lohmann-Hedrich K, Rogaeva E, Schlossmacher MG, Lang AE. Deciphering the role of heterozygous mutations in genes associated with parkinsonism. Lancet Neurol. 2007;6:652-662.

42. Reed X, Bandrés-Ciga S, Blauwendraat C, Cookson MR. The role of monogenic genes in idiopathic Parkinson's disease. Neurobiol Dis. 2019;124:230-239.

43. Hardy J, Lewis P, Revesz T, Lees A, Paisan-Ruiz C. The genetics of Parkinson's syndromes: a critical review. Curr Opin Genet Dev. 2009;19:254-265.

44. Mullin S, Schapira A. The genetics of Parkinson's disease. Br Med Bull. 2015;114:39-52.

45. Blauwendraat $C$, Nalls MA, Singleton AB. The genetic architecture of Parkinson's disease. Lancet Neurol. 2019;4422:1-9.

46. Billingsley KJ, Bandres-Ciga S, Saez-Atienzar S, Singleton AB. Genetic risk factors in Parkinson's disease. Cell Tissue Res. 2018;373:9-20.

47. Toft M, Myhre R, Pielsticker L, White LR, Aasly JO, Farrer MJ. PINK1 mutation heterozygosity and the risk of Parkinson's disease. J Neurol Neurosurg Psychiatry. 2007;78:82-84.

48. Abou-Sleiman PM, Muqit MMK, McDonald NQ, et al. A heterozygous effect for PINK1 mutations in Parkinson's disease? Ann Neurol. 2006;60:414-419.

49. Puschmann A, Fiesel FC, Caulfield TR, et al. Heterozygous PINK1 p.G411S increases risk of Parkinson's disease via a dominant-negative mechanism. Brain. 2017;140:98-117.

50. David HN, Christopher PT, Mark CR. The effects of variants in the PARK2 (parkin), PINK1, and PARK7 (DJ-1) genes along with evidence for their pathogenicity. Curr Protein Pept Sci. 2017;18:702-714. 
51. Lubbe SJ, Escott-Price V, Gibbs JR, et al. Additional rare variant analysis in Parkinson's disease cases with and without known pathogenic mutations: evidence for oligogenic inheritance. Hum Mol Genet. 2016;25:5483-5489.

52. La Cognata V, Morello G, D’Agata V, Cavallaro S. Copy number variability in Parkinson's disease: assembling the puzzle through a systems biology approach. Hum Genet. 2017;136:13-37. 
Box 1. Design of the next-generation sequencing panel.

\begin{tabular}{|c|c|c|c|}
\hline HGNC gene symbol & Inheritance & Disease onset & Role \\
\hline PINK1 & AR & Early-onset & Mitochondrial function/mitophagy \\
\hline PRKN & $A R$ & Early-onset & $\begin{array}{l}\text { Mitochondrial function/mitophagy; } \\
\text { ubiquitination; synaptic function }\end{array}$ \\
\hline PARK7 & AR & Early-onset & $\begin{array}{l}\text { Infl ammation/immune system; } \\
\text { mitochondrial function }\end{array}$ \\
\hline SNCA & $A D$ & Early-onset & $\begin{array}{l}\text { Synaptic function; } \\
\text { autophagy/lysosomal degradation; } \\
\text { mitochondrial function }\end{array}$ \\
\hline$L R R K 2$ & $A D$ & Late-onset & $\begin{array}{l}\text { Synaptic function; } \\
\text { inflammation/immune system; } \\
\text { autophagy/lysosomal degradation }\end{array}$ \\
\hline VPS35 & $A D$ & Late-onset & $\begin{array}{l}\text { Autophagy/lysosomal degradation; } \\
\text { endocytosis }\end{array}$ \\
\hline DCTN1 & $A D$ & NA & $\begin{array}{l}\text { Cell division; axonal transport } \\
\text { (including autophagosomes) }\end{array}$ \\
\hline $\mathrm{GCH}^{\dagger}$ & NA & NA & $\begin{array}{l}\text { GTP binding; calcium ion binding; } \mathrm{BH} 4 \\
\text { metabolism; metabolic pathways }\end{array}$ \\
\hline$G B A^{\dagger}$ & NA & NA & $\begin{array}{l}\text { Inflammation/ immune system; } \\
\text { autophagy/lysosomal degradation; } \\
\text { metabolic pathways }\end{array}$ \\
\hline
\end{tabular}

This article is protected by copyright. All rights reserved 
Table 1. Characteristics of the PD patients.

\begin{tabular}{ll}
\hline Variable & PD (n=189) \\
\hline Clinical subtype & \\
- Tremor-dominant $(\mathrm{n})$ & $43.6 \%(83)$ \\
- Hypokinetic-rigid dominant $(\mathrm{n})$ & $5.3 \%(10)$ \\
- PIGD ( $\mathrm{n})$ & $50.8 \%(96)$ \\
No family history of PD $(\mathrm{n})$ & $83.6 \%(158)$ \\
$1^{\text {st }}$ degree relative with PD $(\mathrm{n})$ & $11.6 \%(22)$ \\
$2^{\text {nd }}$ degree relative with PD $(\mathrm{n})$ & $4.8 \%(9)$ \\
MDS-UPDRS total score, mean $( \pm S D)$ & $72.8(28.8)$ \\
HY, median (range) & $3(1-5)$ \\
SE-ADL, median (range) & $80(30-100)$ \\
BDI, mean ( $\pm S D)$ & $14.8(7.4)$ \\
MMSE, mean $( \pm S D)$ & $26.8(3.5)$
\end{tabular}

Abbrevations: BDI, Beck Depression Inventory; $H Y$, Hoehn and Yahr stage; MDS-UPDRS, Movement Disorders Society Unified Parkinson's Disease Rating Scale; MMSE, Mini Mental State Examination; PD, Parkinson's disease; PIGD, Postural instability and gait disturbance dominant; SE-ADL, Schwab and England Activities of Daily Living Scale.

This article is protected by copyright. All rights reserved 
Table 2. Summary of genetic findings.

\begin{tabular}{|c|c|c|c|c|c|}
\hline Gene & Chromosome & $\begin{array}{l}\text { AA } \\
\text { change }\end{array}$ & Interpretation & $\begin{array}{l}\text { Count } \\
\text { in PD }\end{array}$ & $\begin{array}{l}\text { Count } \\
\text { in } \\
\text { controls }\end{array}$ \\
\hline$G B A$ & 1 & $\begin{array}{l}\text { p.L396P } \\
\text { (allele } \\
\text { name } \\
\text { L444P) }\end{array}$ & $\begin{array}{l}\text { Pathogenic variant } \\
\text { causing Gaucher } \\
\text { disease }\end{array}$ & 1 & 0 \\
\hline$G B A$ & 1 & $\begin{array}{l}\text { pT321M } \\
\text { (allele } \\
\text { name } \\
\text { T369M) }\end{array}$ & Risk variant & 10 & 3 \\
\hline GBA & 1 & $\begin{array}{l}\text { p.E278K } \\
\text { (allele } \\
\text { name } \\
\text { E326K) }\end{array}$ & Risk variant & 6 & 3 \\
\hline$G B A$ & 1 & p.L276I & $\begin{array}{l}\text { Novel variant of } \\
\text { unknown relevance }\end{array}$ & 1 & 0 \\
\hline$G B A$ & 1 & p.E10X & $\begin{array}{l}\text { Novel pathogenic } \\
\text { variant }\end{array}$ & 1 & 0 \\
\hline $\mathrm{GCH} 1$ & 14 & p.V204I & $\begin{array}{l}\text { Likely } \\
\text { pathogenic/Unknown } \\
\text { relevance }\end{array}$ & 2 & 0 \\
\hline GCH1 & 14 & p.Q110E & Unknown relevance & 1 & 0 \\
\hline LRRK2 & 12 & p.E334K & Unknown relevance & 2 & 1 \\
\hline LRRK2 & 12 & p.R767H & Unknown relevance & 1 & 0 \\
\hline
\end{tabular}




$\begin{array}{llllll}\text { LRRK2 } & 12 & \text { p.R1514Q } & \text { Unknown relevance } & 4 & 3 \\ P R K N & 6 & \text { p.V109M } & \text { Unknown relevance } & 1 & 0 \\ P R K N & 6 & \text { p.R126W } & \text { Single heterozygous } & 2 & 0 \\ & & \text { pathogenic variant } & \\ \text { PRKN } & & \text { p.A82E } & \text { Unknown relevance } & 0 & 3 \\ \text { PARK7 } & 1 & \text { p.K186N } & \text { Unknown relevance } & 1 & 0 \\ \text { PINK1 } & 1 & \text { p.G411S } & \text { Unknown relevance } & 1 & 0 \\ \text { PINK1 } & 1 & \text { p.P209L } & \text { Unknown relevance } & 1 & 2 \\ \text { PINK1 } & 1 & \text { p.G51S } & \text { Unknown relevance } & 1 & 0 \\ \text { VPS35 } & 16 & \text { Unknown relevance } & 4 & 1\end{array}$

This article is protected by copyright. All rights reserved 
Table 3. Summary of frequency of any rare variant found.

\begin{tabular}{llll} 
Gene & $\begin{array}{l}\text { Prevalence in PD \% } \\
(\mathbf{n})\end{array}$ & $\begin{array}{l}\text { Prevalence in } \\
\text { controls \% (n) }\end{array}$ & p-value \\
\hline GBA & $10.1(19)$ & $3.8(6)$ & $0.035^{*}$ \\
GCH1 & $1.6(3)$ & $0(0)$ & 0.254 \\
LRRK2 & $3.7(7)$ & $2.5(4)$ & 0.750 \\
PRKN & $1.6(3)$ & $1.9(3)$ & 1 \\
PARK7 & $2.1(4)$ & $0(0)$ & 0.128 \\
PINK1 & $1.6(3)$ & $1.3(2)$ & 1 \\
VPS35 & $0.5(1)$ & $0.6(1)$ & 1
\end{tabular}

* Statistically significant difference

This article is protected by copyright. All rights reserved 